Proceedings

\title{
Association between air pollutants and cancer incidence rates in Japan: An ecological study
}

\author{
Kohei Hasegawa ${ }^{1, *}$, Teruomi Tsukahara ${ }^{1,2}$ and Tetsuo Nomiyama ${ }^{1,2}$ \\ 1 Department of Preventive Medicine and Public Health, School of Medicine, Shinshu University, 3-1-1 Asahi, \\ Matsumoto, Nagano 390-8621, Japan; nomiyama@shinshu-u.ac.jp (T.N.) \\ 2 Department of Occupational Medicine, School of Medicine, Shinshu University, 3-1-1 Asahi, Matsumoto, \\ Nagano 390-8621, Japan; tsukat@shinshu-u.ac.jp (T.T.) \\ * Correspondence: koheih@shinshu-u.ac.jp; Tel.: +81-263-37-2622; Fax: +81-263-37-3499
}

Publisher's Note: MDPI stays neutral with regard to jurisdictional claims in published maps and institutional affiliations.

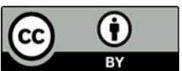

Copyright: (C) 2020 by the authors. Submitted for possible open access publication under the terms and conditions of the Creative Commons Attribution (CC BY) license (http://creativecommons.org/licenses/by/4.0/).

\begin{abstract}
We investigated the associations between the incidence rates of five typical cancer types and five air pollutants in 317 Japanese municipalities in 2017. We obtained the concentrations of the five air pollutants, i.e., sulfur dioxide $\left(\mathrm{SO}_{2}\right)$, nitric oxide $(\mathrm{NO})$, nitric dioxide $\left(\mathrm{NO}_{2}\right)$, photochemical oxidants $\left(\mathrm{O}_{\mathrm{x}}\right)$, and fine particulate matter $\left(\mathrm{PM}_{2.5}\right)$ from Japan's National Institute for Environmental Studies and calculated the yearly mean of each. We identified patients of both sexes with the five most common cancers in Japan's National Cancer Registry, which covers all of the cancer patients in the country. For the males, we included prostate, stomach, colorectal, lung, and liver cancers. For the females, we included breast, colorectal, lung, stomach, and uterine cancers. We calculated the Spearman's correlation coefficients between 25 pairs of air-pollutant concentrations and the agestandardized incidence rate of the cancer types for each sex. We used Poisson regression models to examine the dose-response relationships. We identified 11 significantly positive correlation coefficients at the Bonferroni-corrected alpha level for the five pollutants for the five cancers in both sexes. We observed significantly positive dose-response relationships between $\mathrm{NO}_{2}$ and colorectal cancer and $\mathrm{PM}_{2.5}$ and lung cancer for both sexes. We also observed significant dose-response relationships between $\mathrm{SO}_{2}$ and $\mathrm{PM}_{2.5}$ and liver cancer for the males, and between $\mathrm{NO}$ and lung cancer and $\mathrm{NO}_{2}$ and breast cancer for the females. We did not observe significant associations with prostate, stomach, or uterine cancer. Our findings support the concept that exposure to air pollutants increases cancer incidence rates.
\end{abstract}

Keywords: air pollution, environmental pollution, cancer, environmental epidemiology

\section{Introduction}

Air pollution is a primary public health issue worldwide [1]. Many studies have observed an association between long-term exposure to air pollution and the incidence of lung cancer [2]. In response, the International Agency for Research on Cancer (IARC) classified outdoor air pollution as a Group 1 carcinogen (carcinogenic to humans) in 2013 [3].

The relationships between air pollution and cancers other than lung cancer are less clear [2,4]. For example, colorectal cancer is one of the most prevalent cancers globally [5], but studies on the association between this cancer and air pollution are few in number and have obtained inconsistent results $[4,6,7]$. Laboratory studies have demonstrated a plausible association between air pollution and liver cancer [8], but there have been few epidemiological studies on this topic [9-11] or on cancers other than lung cancer in Japan.

Among the many air pollutants, the adverse effects of exposure to nitric oxide (NO) were rarely examined compared to those of sulfur dioxide $\left(\mathrm{SO}_{2}\right)$, nitric oxide $(\mathrm{NO})$, nitric dioxide $\left(\mathrm{NO}_{2}\right)$, ozone $\left(\mathrm{O}_{3}\right)$, and particular matter $(\mathrm{PM})[2,12]$. Nevertheless, laboratory studies implied that NO might play an essential role in cancer biology $[13,14]$. 
In Japan, the nationwide population-based cancer registry, i.e., the National Cancer Registry (NCR) was established in 2016 under the Cancer Registry Promotion Act of 2013 [15]. This law obligated all of Japan's hospitals and some clinics to report all of the cancer patients encountered therein. The NCR thus enabled the accurate capture of the nationwide cancer incidence for the first time in Japan.

By leveraging data from the NCR, we investigated the association between air pollutants and the incidence rates of five typical cancers.

\section{Methods}

\subsection{Study period and area}

This study was a cross-sectional, ecological investigation. The study period was from January 1 to December 31, 2017. We included 424 municipalities with more than one monitoring station that measured all included air pollutants. We excluded 105 municipalities where all or part of the air pollutant data was missing. To reduce the risk of exposure misclassification, we also excluded two municipalities that were in the designated evacuation area after the Fukushima Daiichi Nuclear Power Plant accident in 2011 [16]. A final total of 317 municipalities were included in this study; they are located throughout the length of Japan.

\subsection{Cancer incidence rates}

We obtained anonymized NCR data from the National Cancer Center Japan (NCCJ). The data included the patients' five-year age group, sex, residence at the time of diagnosis, and the diagnosis coded in the International Classification of Diseases (ICD).

We set the outcome as the incidence of five typical cancer types in Japan [17]. For the males, we included prostate (ICD10: C61, D075), stomach (C16, D002), colorectal (C18C20, D010-D012), lung (C33-C34 or D021-D022), and liver cancers (C22-C24, D015). For the females, we included breast (C50, D050-D059), colorectal, lung, stomach, and uterine cancer (C53-C55, D60-D73). Notably, unlike the previous report [17], we included in situ neoplasms (D00-D09) to increase the sensitivity of the analysis. We excluded patients whose age $(n=8)$ or sex $(n=9)$ data were missing.

We used the age-adjusted cancer incidence rates per million population as the target variables to adjust for the age structure differences between municipalities. We obtained the data of each municipality's population as of January 1, 2017, from the Basic Resident Registry. As the standard reference population, we used the 2000 World Standard Population values [18].

\subsection{Concentrations of air pollutants}

We obtained the monthly data of the concentrations of $\mathrm{SO}_{2}, \mathrm{NO}, \mathrm{NO}_{2}$, photochemical oxidants $\left(\mathrm{O}_{x}\right)$, and fine particulate matter $\left(\mathrm{PM}_{2.5}\right)$ in 2017 from Japan's National Institute for Environmental Studies and calculated the yearly mean. As few monitoring stations in Japan measured $\mathrm{O}_{3}$, we used $\mathrm{O}_{x}$ instead. We considered the data 'missing' when measurements were not available for $>20 \%$ of days in a particular month. We calculated the geometric mean if data from more than one monitoring station were available in a single municipality.

\subsection{Ethical considerations}

The Committee for Medical Ethics of Shinshu University School of Medicine approved the study protocol (approval code: 4700). We performed all of the analyses by using anonymized data, and no participants were contacted.

\subsection{Statical analysis}


To explore the associations between air pollutants and cancer, we calculated Spearman's correlation coefficients between the age-adjusted incidence rates and air pollutants concentrations for each sex. We tested a total of 50 hypotheses and used Bonferroni correction for the multiple testing problems.

For the pairs of pollutant and cancer types that indicated a positive correlation at the Bonferroni-corrected alpha level, we used Poisson regression models to examine the doseresponse [12,19]. We categorized the air pollutant concentrations into four quartiles. We included four other air pollutants as confounders. We considered $p$-values $<0.05$ significant. We performed all of the statistical analyses in R (ver. 4.0.3) [20].

\section{Results and Discussion}

We analyzed the cases of a total of 288,405 individuals diagnosed with cancer in Japan. Table 1 provides the numbers of cases and the age-adjusted incidence rates of each cancer type.

Table 1. The total number of cases and age-adjusted incidence rates per million population of each cancer type in the 317 Japanese municipalities in 2017.

\begin{tabular}{|c|c|c|c|c|c|}
\hline \multicolumn{3}{|c|}{ Male } & \multicolumn{3}{|c|}{ Female } \\
\hline Cancer type & No. of cases & $\begin{array}{c}\text { Age-adjusted } \\
\text { Incidence rate }^{1}\end{array}$ & Cancer type & No. of cases & $\begin{array}{l}\text { Age-adjusted } \\
\text { Incidence rate }^{1}\end{array}$ \\
\hline Prostate & 35,247 & 55.71 & Breast & 42,823 & 99.32 \\
\hline Stomach & 33,733 & 55.88 & Colorectal & 31,996 & 48.41 \\
\hline Colorectal & 45,832 & 84.80 & Lung & 16,276 & 22.52 \\
\hline Lung & 32,129 & 52.60 & Stomach & 15,250 & 20.40 \\
\hline Liver & 14,614 & 24.04 & Uterine & 20,505 & 67.36 \\
\hline
\end{tabular}

${ }^{1}$ Adjusted for the 2000 World Standard Population proportion.

Table 2 shows the air pollution levels by mean and quartiles and Spearman's correlation coefficients between air pollutants in the 317 Japanese municipalities in 2017. The mean concentrations of the air pollutants were as follows: $\mathrm{SO}_{2}, 1.52 \mathrm{ppb}$; $\mathrm{NO}, 2.31 \mathrm{ppb}$; $\mathrm{NO}_{2}$, $9.34 \mathrm{ppb} ; \mathrm{O}_{x}, 35.16 \mathrm{ppb}$; and $\mathrm{PM}_{2.5} 11.56 \mu \mathrm{g} / \mathrm{m}^{3} . \mathrm{SO}_{2}, \mathrm{NO}, \mathrm{NO}_{2}$, and $\mathrm{PM}_{2.5}$ were positively correlated, but $\mathrm{O}_{x}$ showed negative correlations with the other pollutants.

Table 2. Air pollution levels and Spearman's correlation coefficients between air pollutants in 317 Japanese municipalities in 2017.

\begin{tabular}{|c|c|c|c|c|c|c|c|c|c|c|}
\hline \multirow[b]{2}{*}{$\begin{array}{c}\text { Air pollutant } \\
\text { unit }\end{array}$} & \multirow[b]{2}{*}{ Mean (SD) } & \multicolumn{3}{|c|}{ Quartile } & \multicolumn{6}{|c|}{ Spearman's correlation coefficient } \\
\hline & & Q1 & Q2 & Q3 & & $\mathrm{SO}_{2}$ & NO & $\mathrm{NO}_{2}$ & $\mathbf{O}_{x}$ & $\mathbf{P M}_{2.5}$ \\
\hline $\mathrm{SO}_{2}, \mathrm{ppb}$ & $1.52(1.03)$ & 0.92 & 1.25 & 2.00 & $\mathrm{SO}_{2}$ & - & $0.26^{*}$ & $0.32^{*}$ & $-0.11^{*}$ & $0.25^{*}$ \\
\hline $\mathrm{NO}, \mathrm{ppb}$ & $2.31(1.59)$ & 1.08 & 2.00 & 3.17 & NO & & - & $0.82^{*}$ & $-0.61^{*}$ & $0.22^{*}$ \\
\hline $\mathrm{NO}_{2}, \mathrm{ppb}$ & $9.34(4.30)$ & 5.96 & 8.67 & 12.50 & $\mathrm{NO}_{2}$ & & & - & $-0.57^{*}$ & $0.22^{*}$ \\
\hline $\mathrm{O}_{x,} \mathrm{ppb}$ & $35.16(3.20)$ & 33.21 & 34.92 & 36.92 & $\mathrm{O}_{\mathrm{x}}$ & & & & - & -0.01 \\
\hline $\mathrm{PM}_{2.5}, \mu \mathrm{g} / \mathrm{m}^{3}$ & $11.56(2.29)$ & 10.11 & 11.62 & 13.06 & $\mathrm{PM}_{2.5}$ & & & & & - \\
\hline
\end{tabular}

Table 3 lists the Spearman's correlation coefficients between the age-adjusted cancer incidence rates and the air pollutant concentrations. A total of 18 correlation coefficients were significantly positive at an alpha level of 0.05 , and 11 of them remained significant at the level of Bonferroni correlation of 0.001 . 
Table 3. Spearman's correlation coefficients between the age-adjusted cancer incidence of five typical cancer types and the air pollutants stratified by sex.

\begin{tabular}{|c|c|c|c|c|c|c|c|c|c|c|c|}
\hline \multirow[b]{2}{*}{ Cancer type } & \multicolumn{5}{|c|}{ Male } & \multirow[b]{2}{*}{$\begin{array}{c}\text { Cancer } \\
\text { type }\end{array}$} & \multicolumn{5}{|c|}{ Female } \\
\hline & $\mathrm{SO}_{2}$ & NO & $\mathrm{NO}_{2}$ & $\mathrm{O}_{\mathrm{x}}$ & $\mathbf{P M}_{2.5}$ & & $\mathrm{SO}_{2}$ & NO & $\mathrm{NO}_{2}$ & $\mathbf{O}_{x}$ & $\mathrm{PM}_{2.5}$ \\
\hline Prostate & 0.01 & 0.09 & $0.15^{\mathrm{a}}$ & -0.08 & $-0.14^{a}$ & Breast & $0.19 b$ & $0.34^{\mathrm{b}}$ & $0.39 \mathrm{~b}$ & $-0.24^{b}$ & 0.08 \\
\hline Stomach & -0.03 & $-0.12^{a}$ & -0.07 & 0.10 & -0.04 & Colorectal & 0.05 & $0.25^{\mathrm{b}}$ & $0.30^{\mathrm{b}}$ & $-0.23^{b}$ & -0.03 \\
\hline Colorectal & 0.02 & $0.14^{\mathrm{a}}$ & $0.19^{b}$ & $-0.17^{a}$ & -0.03 & Lung & $0.11^{\mathrm{a}}$ & $0.20^{\mathrm{b}}$ & $0.18^{\mathrm{a}}$ & -0.07 & $0.21^{\mathrm{b}}$ \\
\hline Lung & 0.05 & 0.09 & 0.08 & -0.03 & $0.26^{b}$ & Stomach & 0.01 & -0.06 & -0.04 & 0.09 & $-0.12^{a}$ \\
\hline Liver & $0.20^{\mathrm{b}}$ & -0.03 & -0.11 & $0.12^{\mathrm{a}}$ & $0.42^{\mathrm{b}}$ & Uterine & $0.12^{\mathrm{a}}$ & $-0.12^{a}$ & $-0.15^{\mathrm{a}}$ & 0.09 & $0.17^{a}$ \\
\hline
\end{tabular}

aSignificant at an alpha level of 0.05. bSignificant at the Bonferroni-corrected alpha level of 0.001.

Table 4 provides the results of Poisson regression models of 11 pollutant-cancer pairs. We observed positive dose-response relationships between $\mathrm{NO}_{2}$ and colorectal cancer and between $\mathrm{PM}_{2.5}$ and lung cancer for both sexes. For the males, $\mathrm{SO}_{2}$ and $\mathrm{PM}_{2.5}$ also showed positive dose-response relationships with liver cancer. For the females, $\mathrm{NO}$ and lung cancer and $\mathrm{NO}_{2}$ and breast cancer also showed positive dose-response relationships.

Table 4. Poisson regression analysis of selected pairs between air pollutants and cancer types.

\begin{tabular}{|c|c|c|c|c|c|c|}
\hline \multirow{2}{*}{ Cancer type (sex) } & \multicolumn{2}{|c|}{ Liver (male) } & \multicolumn{2}{|c|}{ Breast (female) } & & \\
\hline & $\mathrm{RR}^{\mathrm{a}}(95 \% \mathrm{CI})$ & $p$ & $\mathrm{RR}^{\mathrm{a}}(95 \% \mathrm{CI})$ & $p$ & & \\
\hline \multicolumn{7}{|l|}{$\mathrm{SO}_{2}$ conc., $\mathrm{ppb}$} \\
\hline$\leq 0.92$ & 1.00 & & 1.00 & & & \\
\hline $0.92-1.25$ & $0.99(0.92-1.05)$ & 0.71 & $1.05(1.01-1.08)$ & $<0.01$ & & \\
\hline $1.25-2.00$ & $1.07(1.00-1.14)$ & 0.04 & $1.03(1.00-1.07)$ & 0.06 & & \\
\hline$>2.00$ & $1.08(1.01-1.15)$ & 0.03 & $1.02(0.99-1.06)$ & 0.17 & & \\
\hline$p$ for trend & \multicolumn{2}{|r|}{$<0.01$} & \multicolumn{2}{|c|}{0.25} & & \\
\hline \multirow{2}{*}{ Cancer type (sex) } & \multicolumn{2}{|c|}{ Breast (female) } & \multicolumn{2}{|c|}{ Colorectal (female) } & \multicolumn{2}{|c|}{ Lung (female) } \\
\hline & $\mathrm{RR}^{\mathrm{a}}(95 \% \mathrm{CI})$ & $p$ & $\mathrm{RR}^{\mathrm{a}}(95 \% \mathrm{CI})$ & $p$ & $\mathrm{RR}^{\mathrm{a}}(95 \% \mathrm{CI})$ & $p$ \\
\hline \multicolumn{7}{|l|}{ NO conc., ppb } \\
\hline$\leq 1.08$ & 1.00 & & 1.00 & & 1.00 & \\
\hline $1.08-2.00$ & $1.05(1.01-1.08)$ & $<0.01$ & $0.97(0.92-1.02)$ & 0.19 & $1.02(0.95-1.10)$ & 0.56 \\
\hline $2.00-3.17$ & $1.03(1.00-1.07)$ & 0.06 & $1.01(0.95-1.08)$ & 0.67 & $1.08(0.99-1.18)$ & 0.09 \\
\hline$>3.17$ & $1.02(0.99-1.06)$ & 0.17 & $1.00(0.92-1.08)$ & 0.93 & $1.13(1.01-1.26)$ & 0.04 \\
\hline$p$ for trend & & 0.25 & & 0.76 & & 0.03 \\
\hline \multirow{2}{*}{ Cancer type (sex) } & \multicolumn{2}{|c|}{ Colorectal (male) } & \multicolumn{2}{|c|}{ Breast (female) } & \multicolumn{2}{|c|}{ Colorectal (female) } \\
\hline & $\mathrm{RR}^{\mathrm{a}}(95 \% \mathrm{CI})$ & $p$ & $\mathrm{RR}^{\mathrm{a}}(95 \% \mathrm{CI})$ & $p$ & $\mathrm{RR}^{\mathrm{a}}(95 \% \mathrm{CI})$ & $p$ \\
\hline \multicolumn{7}{|l|}{$\mathrm{NO}_{2}$ conc., ppb } \\
\hline$\leq 5.96$ & 1.00 & & 1.00 & & 1.00 & \\
\hline $5.96-8.67$ & $0.98(0.94-1.02)$ & 0.25 & $1.01(0.97-1.04)$ & 0.76 & $1.13(1.08-1.19)$ & $<0.01$ \\
\hline $8.67-12.50$ & $1.01(0.97-1.05)$ & 0.59 & $1.09(1.05-1.14)$ & $<0.01$ & $1.12(1.06-1.18)$ & $<0.01$ \\
\hline$>12.50$ & $1.11(1.05-1.17)$ & $<0.01$ & $1.20(1.14-1.26)$ & $<0.01$ & $1.24(1.15-1.33)$ & $<0.01$ \\
\hline$p$ for trend & & $<0.01$ & & $<0.01$ & & $<0.01$ \\
\hline \multirow{2}{*}{ Cancer type (sex) } & \multicolumn{2}{|c|}{ Lung (male) } & \multicolumn{2}{|c|}{ Liver (male) } & \multicolumn{2}{|c|}{ Lung (female) } \\
\hline & $\mathrm{RR}^{\mathrm{a}}(95 \% \mathrm{CI})$ & $p$ & $\mathrm{RR}^{\mathrm{a}}(95 \% \mathrm{CI})$ & $p$ & $\operatorname{RR}^{\mathrm{a}}(95 \% \mathrm{CI})$ & $p$ \\
\hline \multicolumn{7}{|l|}{$\mathrm{PM}_{2.5}$ conc., $\mu \mathrm{g} / \mathrm{m} 3$} \\
\hline$\leq 10.11$ & 1.00 & & 1.00 & & 1.00 & \\
\hline $10.11-11.62$ & $1.01(0.97-1.06)$ & 0.63 & $1.05(0.98-1.13)$ & 0.13 & $0.97(0.90-1.04)$ & 0.37 \\
\hline $11.62-13.06$ & $1.05(1.00-1.10)$ & 0.05 & $1.17(1.09-1.25)$ & $<0.01$ & $1.07(1.00-1.15)$ & 0.06 \\
\hline$>13.06$ & $1.12(1.07-1.17)$ & $<0.01$ & $1.38(1.29-1.48)$ & $<0.01$ & $1.10(1.03-1.18)$ & $<0.01$ \\
\hline$p$ for trend & & $<0.01$ & & $<0.01$ & & $<0.01$ \\
\hline
\end{tabular}

aAdjusted for age and the other four air pollutants. CI: confidence interval, RR: relative risk.

In this ecological study, we examined the associations between air pollutants and cancer incidence rates in 317 Japanese municipalities, and our analyses revealed significant positive dose-response relationships in some pollutant-cancer pairs.

The association between lung cancer and air pollution is well established [2,21]. In accord with previous reports, we observed positive correlations between lung cancer and all of the included pollutants except $\mathrm{O}_{x}$. Dose-response relationships between lung cancer and $\mathrm{PM}_{2.5}$ were present after adjusting for other air pollutants in both sexes. Our results thus 
provide further evidence of the associations between air pollutants - especially $\mathrm{PM}_{2.5}-$ and lung cancer.

As noted above, there have been few investigations of the relationship between air pollutants and cancer types other than lung cancer, but those investigations have suggested some associations. An analysis of the Cancer Prevention Study II results examined the associations between $\mathrm{PM}_{2.5}, \mathrm{NO}_{2}$, and $\mathrm{O}_{3}$ and many cancer types; only the relationships between $\mathrm{PM}_{2.5}$ and kidney cancer, $\mathrm{PM}_{2.5}$ and bladder cancer, and $\mathrm{NO}_{2}$ and colorectal cancer were significant [4]. A study of $\mathrm{PM}_{2.5}$ exposure in Taiwan reported that PM2.5 was associated with gastrointestinal, liver, and colorectal cancers but not stomach cancer [22]. Positive correlations between PM and lung, breast, uterine, and ovarian cancers but not other types of cancer were obtained in a study of PM exposure in Japan [23]. A 2018 review demonstrated that breast cancer was associated with $\mathrm{NO}_{2}$ and less clearly with $\mathrm{PM}_{2.5}$ [24]. The present study's results are similar to those of the previous studies in general, and some additional associations were revealed for the first time in the Japanese population.

Among the air pollutants, examinations of NO in epidemiological studies are scarce. We observed a positive dose-response relationship between NO and lung cancer in the female population in this study. An ecological study from Taiwan reported a positive association between NO and lung cancer of a specific cell type [12]. Further investigations are necessary to determine the above-described associations by using individual-level data.

There are several study limitations to address. This was a cross-sectional, ecological study. We observed significant correlations, but this does not establish an individual-level association or causation. We considered confounding by age and sex, but we did not consider other known confounders, such as smoking for lung cancer and human papillomavirus infection for cervical cancer, and unknown confounders. Thus, the observed associations could be the results of factors other than air pollution. In the study's design, we assumed that the patients lived in the municipality for most of their lives, and that the yearly mean air pollutants concentrations in 2017 reasonably reflect the patients' long-term exposure. We observed strong positive correlations between the yearly mean concentration in 2017 and the 5-year mean concentration in 2012-2016 among 71 monitors $\left(\mathrm{SO}_{2}, r=0.86\right.$; $\mathrm{NO}$, $\left.r=0.94 ; \mathrm{NO}_{2}, r=0.98 ; \mathrm{O}_{x}, r=0.84 ; \mathrm{PM}_{2.5}, r=0.82\right)$. However, this assumption may have caused exposure misclassifications and biased our results.

\section{Conclusions}

Our findings support the concept that exposure to air pollutants increases cancer incidence rates.

Author Contributions: Conceptualization, K.H., T.T., and T.N.; methodology, K.H.; software, K.H.; validation, T.T., and T.N.; formal analysis, K.H.; investigation, K.H.; resources, K.H.; data curation, K.H.; writing - original draft preparation, K.H.; writing - review and editing, T.T. and T.N.; supervision, T.T.; project administration, T.N.; All authors have read and agreed to the published version of the manuscript.

Funding: This research received no external funding.

Acknowledgments: We thank the NCCJ for managing and providing the NCR data.

Conflicts of Interest: The authors declare no conflict of interest.

\section{References}

1. GBD 2017 Risk Factor Collaborators Global, regional, and national comparative risk assessment of 84 behavioural, environmental and occupational, and metabolic risks or clusters of risks for 195 countries and territories, 1990-2017: a systematic analysis for the Global Burden of Disease Study 2017. Lancet Lond. Engl. 2018, 392, 1923-1994, doi:10.1016/S0140-6736(18)32225-6.

2. Turner, M.C.; Andersen, Z.J.; Baccarelli, A.; Diver, W.R.; Gapstur, S.M.; Pope, C.A.; Prada, D.; Samet, J.; Thurston, G.; Cohen, A. Outdoor air pollution and cancer: An overview of the current evidence and public health recommendations. CA. Cancer $J$. Clin. 2020, 70, 460-479, doi:10.3322/caac.21632.

3. Loomis, D.; Grosse, Y.; Lauby-Secretan, B.; Ghissassi, F.E.; Bouvard, V.; Benbrahim-Tallaa, L.; Guha, N.; Baan, R.; Mattock, H.; Straif, K. The carcinogenicity of outdoor air pollution. Lancet Oncol. 2013, 14, 1262-1263, doi:10.1016/S1470-2045(13)70487-X. 
4. Turner, M.C.; Krewski, D.; Diver, W.R.; Pope, C.A.; Burnett, R.T.; Jerrett, M.; Marshall, J.D.; Gapstur, S.M. Ambient Air Pollution and Cancer Mortality in the Cancer Prevention Study II. Environ. Health Perspect. 2017, 125, 087013, doi:10.1289/EHP1249.

5. Bray, F.; Ferlay, J.; Soerjomataram, I.; Siegel, R.L.; Torre, L.A.; Jemal, A. Global cancer statistics 2018: GLOBOCAN estimates of incidence and mortality worldwide for 36 cancers in 185 countries. CA. Cancer J. Clin. 2018, 68, 394-424, doi:10.3322/caac.21492.

6. Wong, C.M.; Tsang, H.; Lai, H.K.; Thomas, G.N.; Lam, K.B.; Chan, K.P.; Zheng, Q.; Ayres, J.G.; Lee, S.Y.; Lam, T.H.; et al. Cancer Mortality Risks from Long-term Exposure to Ambient Fine Particle. Cancer Epidemiol. Biomark. Prev. Publ. Am. Assoc. Cancer Res. Cosponsored Am. Soc. Prev. Oncol. 2016, 25, 839-845, doi:10.1158/1055-9965.EPI-15-0626.

7. Ancona, C.; Badaloni, C.; Mataloni, F.; Bolignano, A.; Bucci, S.; Cesaroni, G.; Sozzi, R.; Davoli, M.; Forastiere, F. Mortality and morbidity in a population exposed to multiple sources of air pollution: A retrospective cohort study using air dispersion models. Environ. Res. 2015, 137, 467-474, doi:10.1016/j.envres.2014.10.036.

8. Kim, J.W.; Park, S.; Lim, C.W.; Lee, K.; Kim, B. The Role of Air Pollutants in Initiating Liver Disease. Toxicol. Res. 2014, 30, 6570, doi:10.5487/TR.2014.30.2.065.

9. Pan, W.-C.; Wu, C.-D.; Chen, M.-J.; Huang, Y.-T.; Chen, C.-J.; Su, H.-J.; Yang, H.-I. Fine Particle Pollution, Alanine Transaminase, and Liver Cancer: A Taiwanese Prospective Cohort Study (REVEAL-HBV). JNCI J. Natl. Cancer Inst. 2016, 108, doi:10.1093/jnci/djv341.

10. Pedersen, M.; Andersen, Z.J.; Stafoggia, M.; Weinmayr, G.; Galassi, C.; Sørensen, M.; Eriksen, K.T.; Tjønneland, A.; Loft, S.; Jaensch, A.; et al. Ambient air pollution and primary liver cancer incidence in four European cohorts within the ESCAPE project. Environ. Res. 2017, 154, 226-233, doi:10.1016/j.envres.2017.01.006.

11. VoPham, T.; Bertrand, K.A.; Tamimi, R.M.; Laden, F.; Hart, J.E. Ambient PM2.5 air pollution exposure and hepatocellular carcinoma incidence in the United States. Cancer Causes Control 2018, 29, 563-572, doi:10.1007/s10552-018-1036-x.

12. Liaw, Y.-P.; Ting, T.-F.; Ho, C.-C.; Chiou, Z.-Y. Cell type specificity of lung cancer associated with nitric oxide. Sci. Total Environ. 2010, 408, 4931-4934, doi:10.1016/j.scitotenv.2010.06.023.

13. Lala, P.K.; Chakraborty, C. Role of nitric oxide in carcinogenesis and tumour progression. Lancet Oncol. 2001, 2, 149-156, doi:10.1016/S1470-2045(00)00256-4.

14. Sanuphan, A.; Chunhacha, P.; Pongrakhananon, V.; Chanvorachote, P. Long-term nitric oxide exposure enhances lung cancer cell migration. BioMed Res. Int. 2013, 2013, 186972-186972, doi:10.1155/2013/186972.

15. CANCER STATISTICS IN JAPAN '17. Available online: https://ganjoho.jp/en/professional/statistics/brochure/2017_en.html (accessed on Dec 1, 2020).

16. Transition of evacuation designated zones. Available online: https://www.pref.fukushima.lg.jp/site/portal-english/en0308.html (accessed on Dec 1, 2020).

17. Cancer incidence of Japan 2017. Available online: https://www.mhlw.go.jp/content/10900000/000624853.pdf (accessed on Dec 1, 2020).

18. Ahmad, O.B.; Boschi-Pinto, C.; Lopez, A.D.; Murray, C.J.L.; Lozano, R.; Inoue, M. AGE STANDARDIZATION OF RATES: A NEW WHO STANDARD.; 2000.

19. Huang, H.-H.; Huang, J.-Y.; Lung, C.-C.; Wu, C.-L.; Ho, C.-C.; Sun, Y.-H.; Ko, P.-C.; Su, S.-Y.; Chen, S.-C.; Liaw, Y.-P. Cell-type specificity of lung cancer associated with low-dose soil heavy metal contamination in Taiwan: An ecological study. BMC Public Health 2013, 13, 330, doi:10.1186/1471-2458-13-330.

20. R Core Team R: A Language and Environment for Statistical Computing; R Foundation for Statistical Computing: Vienna, Austria, 2019;

21. Outdoor air pollution; IARC Working Group on the Evaluation of Carcinogenic Risks to Humans, Ed.; IARC monographs on the evaluation of carcinogenic risks to humans; International Agency for Research on Cancer, World Health Organization: Lyon, France, 2016; ISBN 978-92-832-0147-2.

22. Guo, C.; Chan, T.-C.; Teng, Y.-C.; Lin, C.; Bo, Y.; Chang, L.; Lau, A.K.H.; Tam, T.; Wong, M.C.S.; Qian Lao, X. Long-term exposure to ambient fine particles and gastrointestinal cancer mortality in Taiwan: A cohort study. Environ. Int. 2020, 138, 105640, doi:10.1016/j.envint.2020.105640.

23. Iwai, K.; Mizuno, S.; Miyasaka, Y.; Mori, T. Correlation between suspended particles in the environmental air and causes of disease among inhabitants: Cross-sectional studies using the vital statistics and air pollution data in Japan. Environ. Res. 2005, 99, 106-117, doi:10.1016/j.envres.2004.11.004.

24. White, A.J.; Bradshaw, P.T.; Hamra, G.B. Air Pollution and Breast Cancer: a Review. Curr. Epidemiol. Rep. 2018, 5, 92-100, doi:10.1007/s40471-018-0143-2. 